\#USGS

The Fort Collins Science Center 
It takes interdisciplinary, well-integrated science teams to fully address the complex natural resource issues that managers face today. 

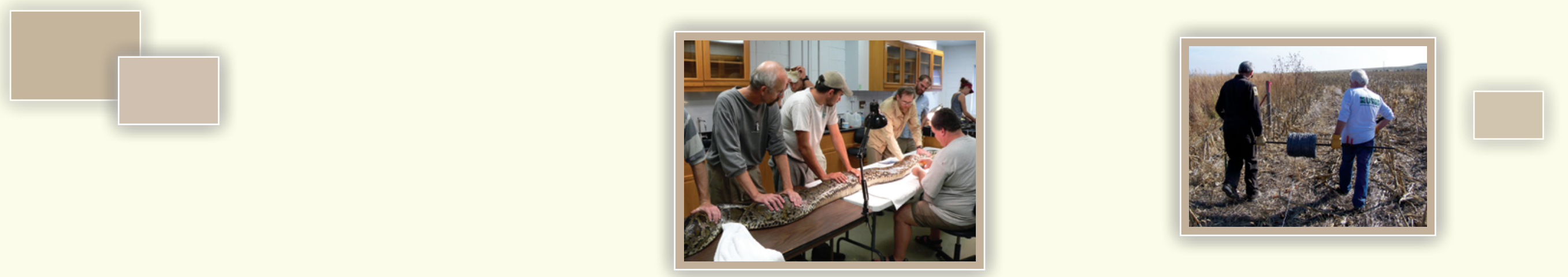

At the Fort Collins Science Center,

this is what we do.

We build these teams.

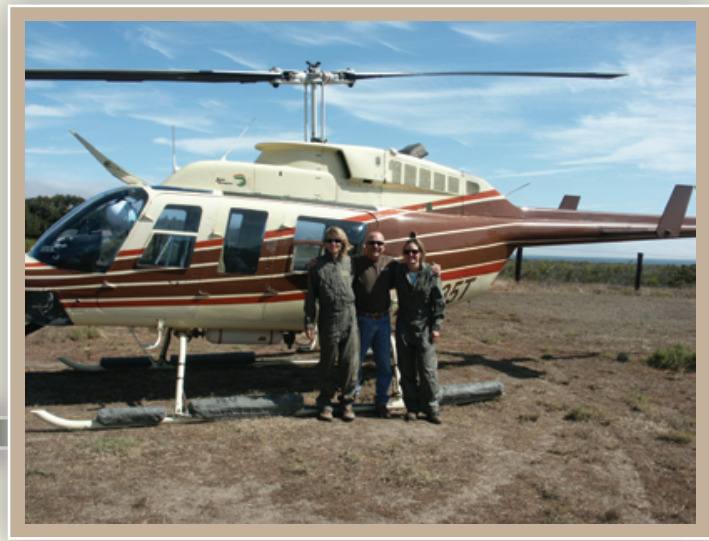




\section{Water for Life}

Competing demands for water can result in alteration or loss of critical riverine, riparian,

and wetland habitats. As stewards of our Nation's natural resources, land and water management agencies are responsible for balancing use and conservation of water resources. Managers need quantitative, objective, science-based information that helps them manage, conserve, and plan for the Nation's water resources and the species and habitats they support.

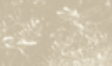

$(1-3)=2$

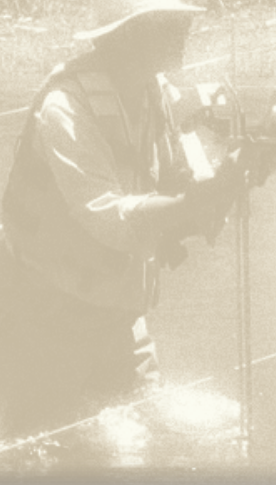

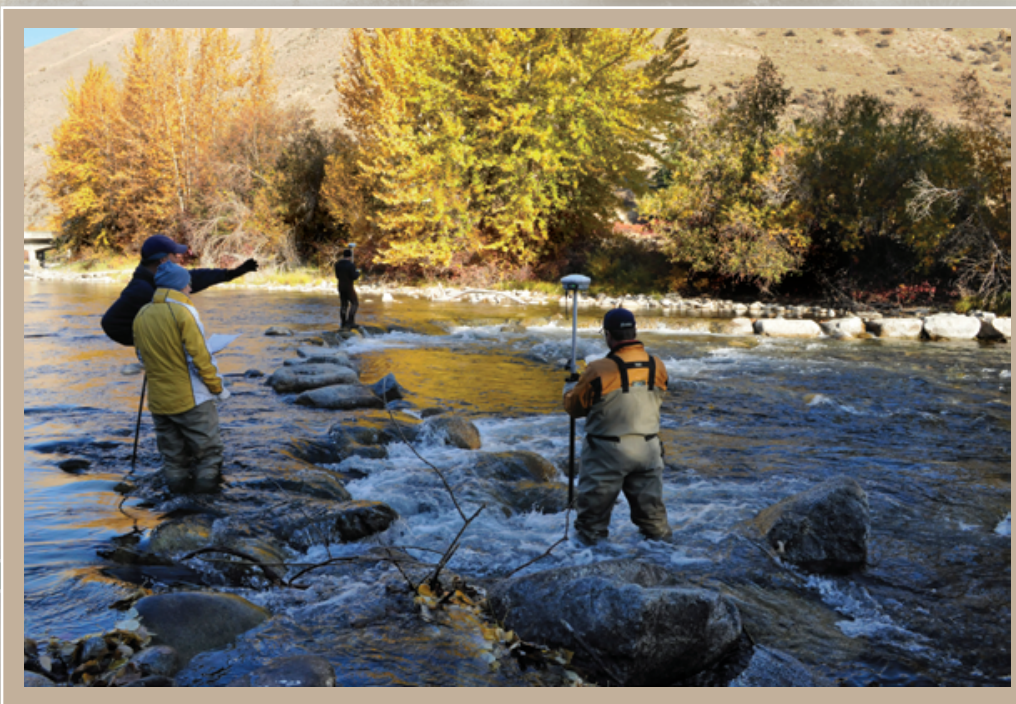

The Aquatic Systems scientists at FORT

investigate aquatic populations, communities,

ecosystems, and landscapes, particularly how

the goods and services these systems provide are

affected by changes in flow, sediment, invasive

pecies, and climate. We develop tools and

methodologies that managers and scientists can use

to assess status and understand the interplays of

physical, biogeochemical, and biological processes

the possible outcomes of management actions; and

likely ecological responses.

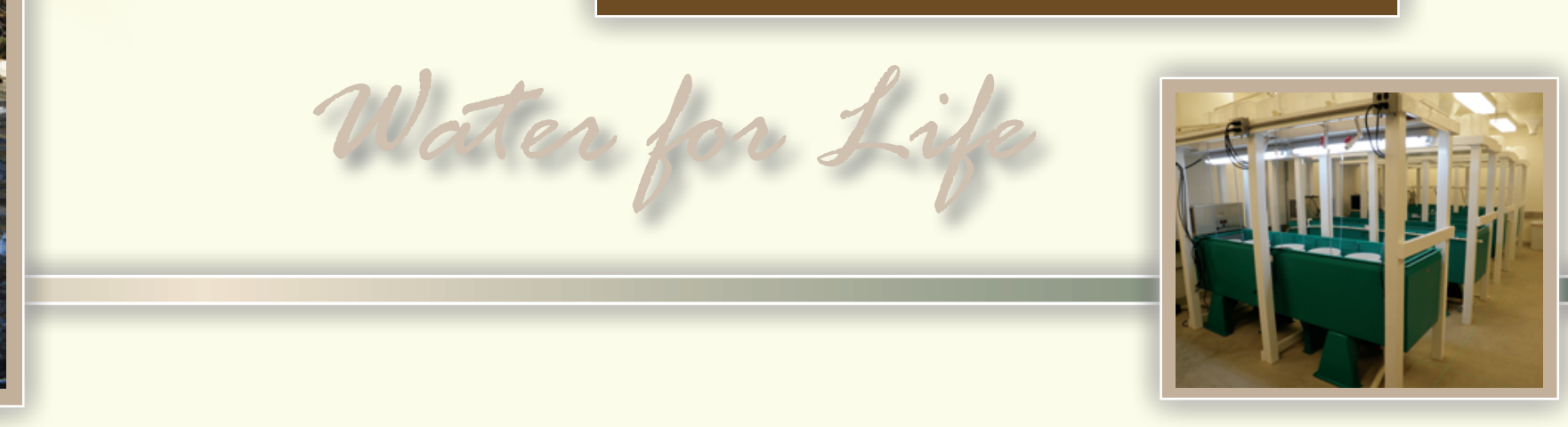

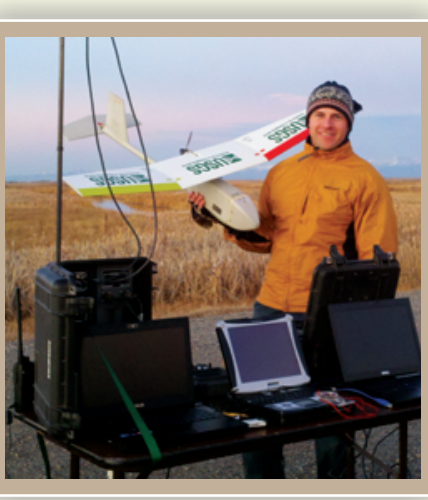

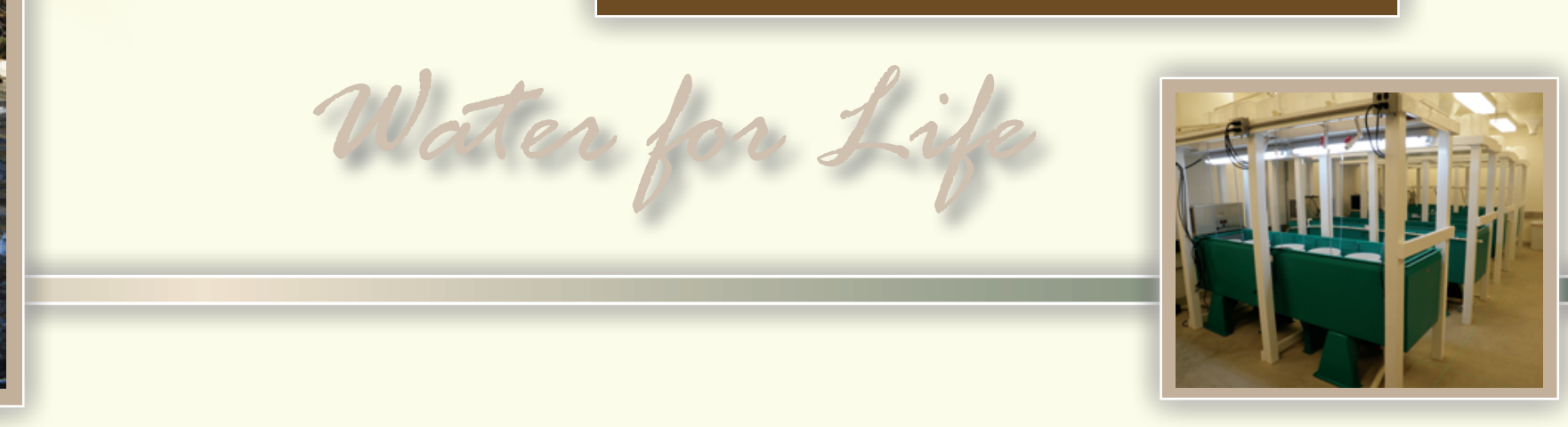

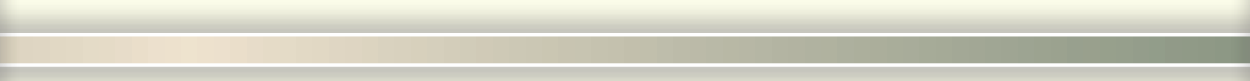

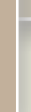




\section{The Dynamics of Change}

Environmental disturbances, such as climate change, energy and residential development, invasive species, and many others, can result in ecosystem-level changes. Therefore, natural resource managers need to consider the dynamic web of interactions among ecosystem components. The complexity of ecosystem responses over space and time demands an interdisciplinary approach that integrates both biotic and abiotic processes.

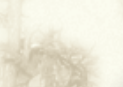

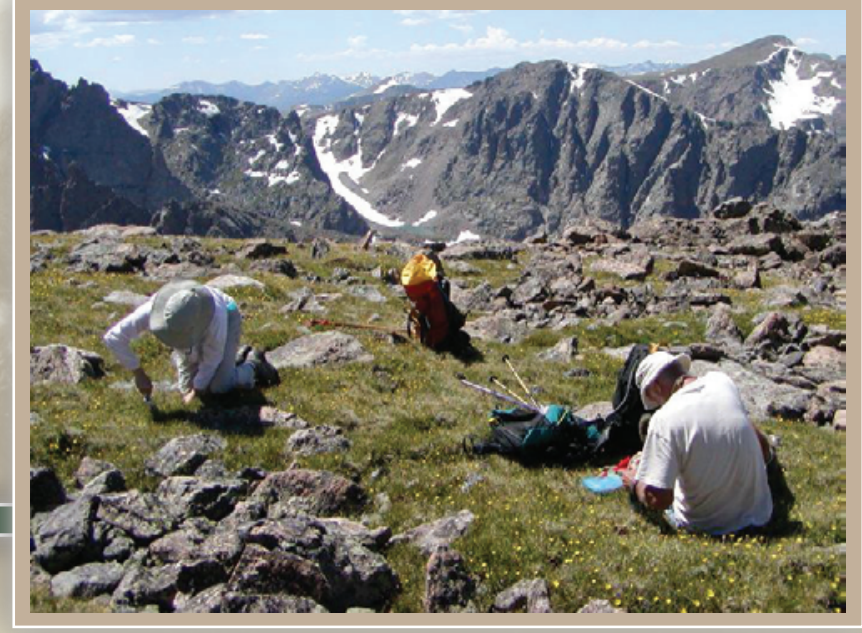

\section{The Dypamanies of Change}

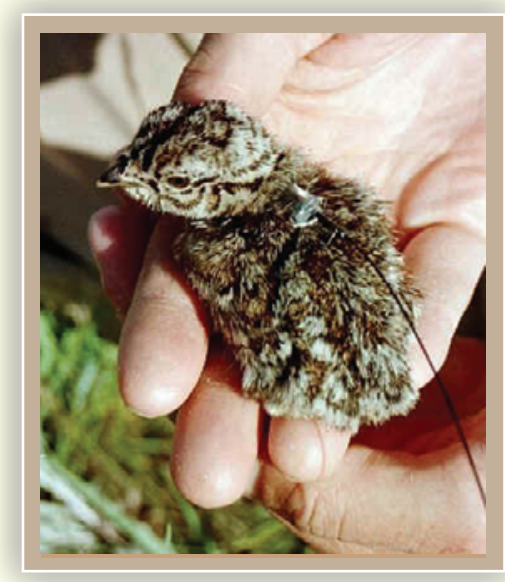

Focusing on the U.S. West, FORT's

Ecosystem Dynamics scientists

specialize in quantifying ecosystem

patterns and processes from loc

to landscape scales. We provide

research and technical assistance to

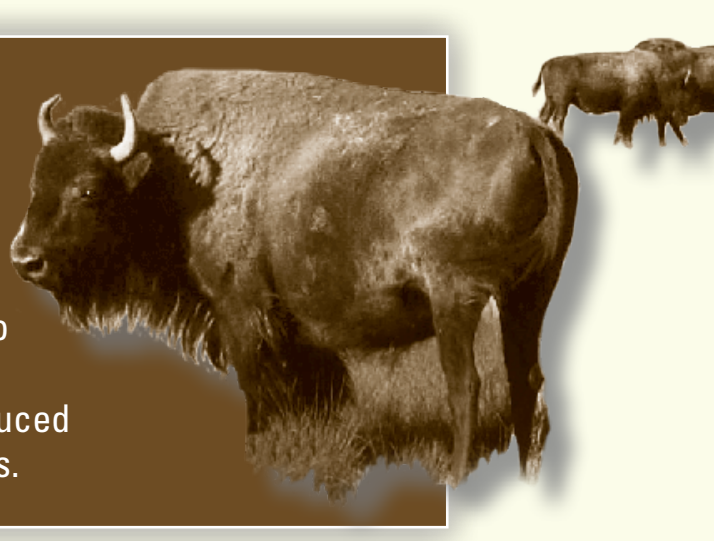

responses to natural and human-induced

changes affecting terrestrial systems.

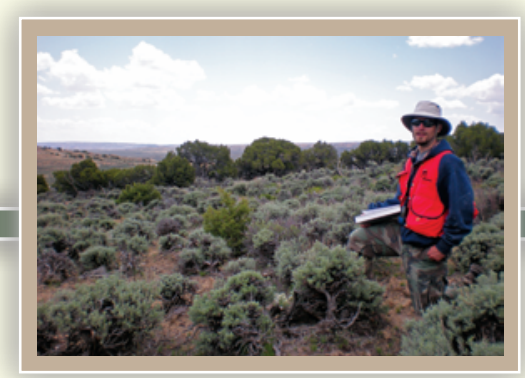




\section{Information Overload, Reloaded}

Data are everywhere. Aggregating information in a way that it is easily accessed, managed, used, and understood, however, is a significant challenge. Natural resource agencies need information systems and services to help managers integrate and analyze data, visualize outcomes, and apply scientific data and information to natural resource issues.
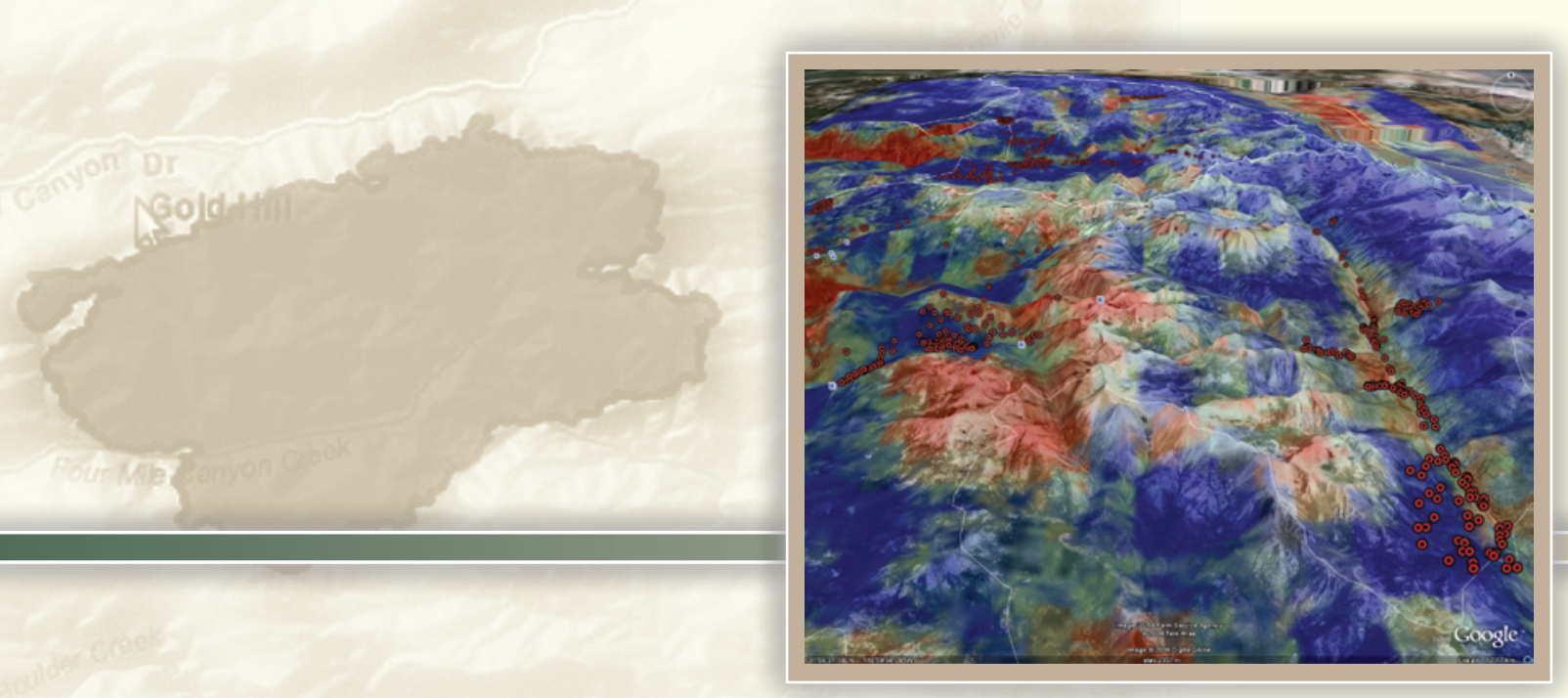

\section{Tiffermation Overlead}

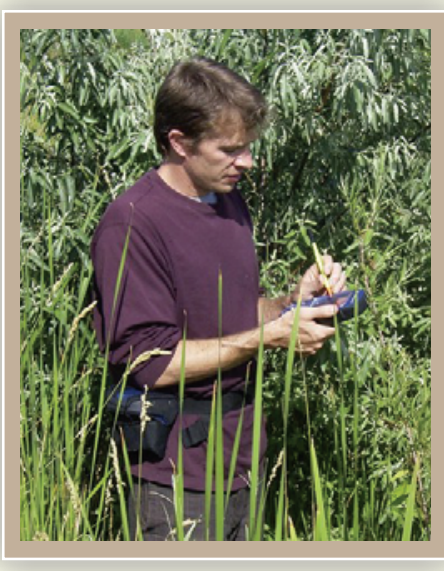

FORT's Information Science "N.SW

specialists make up a large pool of

experienced and innovative technical

staff that produces Web and geospatia

applications, tools, analyses, and other

products. Scientists and managers use

these products to assemble, analyze, and

share critical information and to inform

resource management decisions.
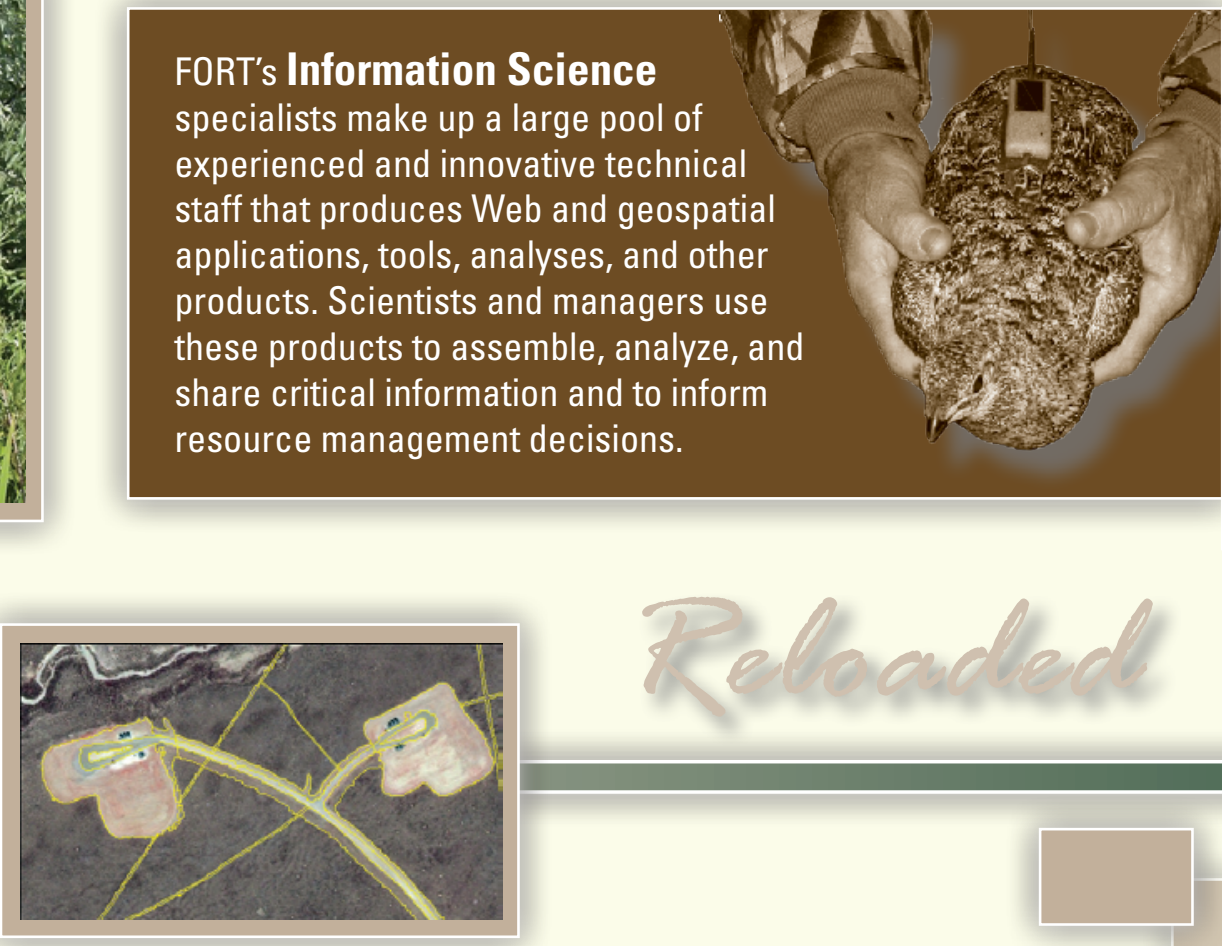


\section{Making Science Relevant to People}

Social and economic research provides public land and resource managers with information to make scientifically sound, socially supported decisions. Many conservation planning documents and environmental impact statements require data on the socioeconomic effects of management actions. These actions affect recreational and commercial users, surrounding communities, and the Nation as a whole.
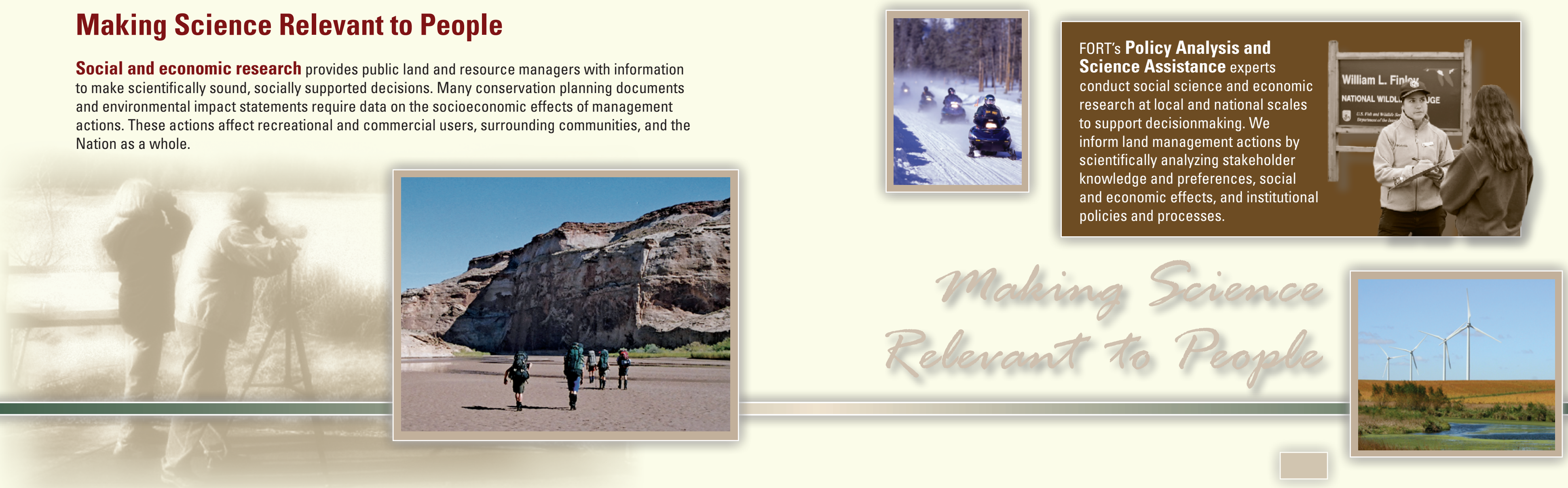


\section{Their Future Depends, in Part, on Us}

Recovery of imperiled species requires a scientific understanding of their life histories, habitat requirements, distribution and abundance, and factors limiting their success. Some of the biggest challenges to species recovery and conservation involve changes to their environment, including land-use change, disease, climate change, energy development, and invasive species.

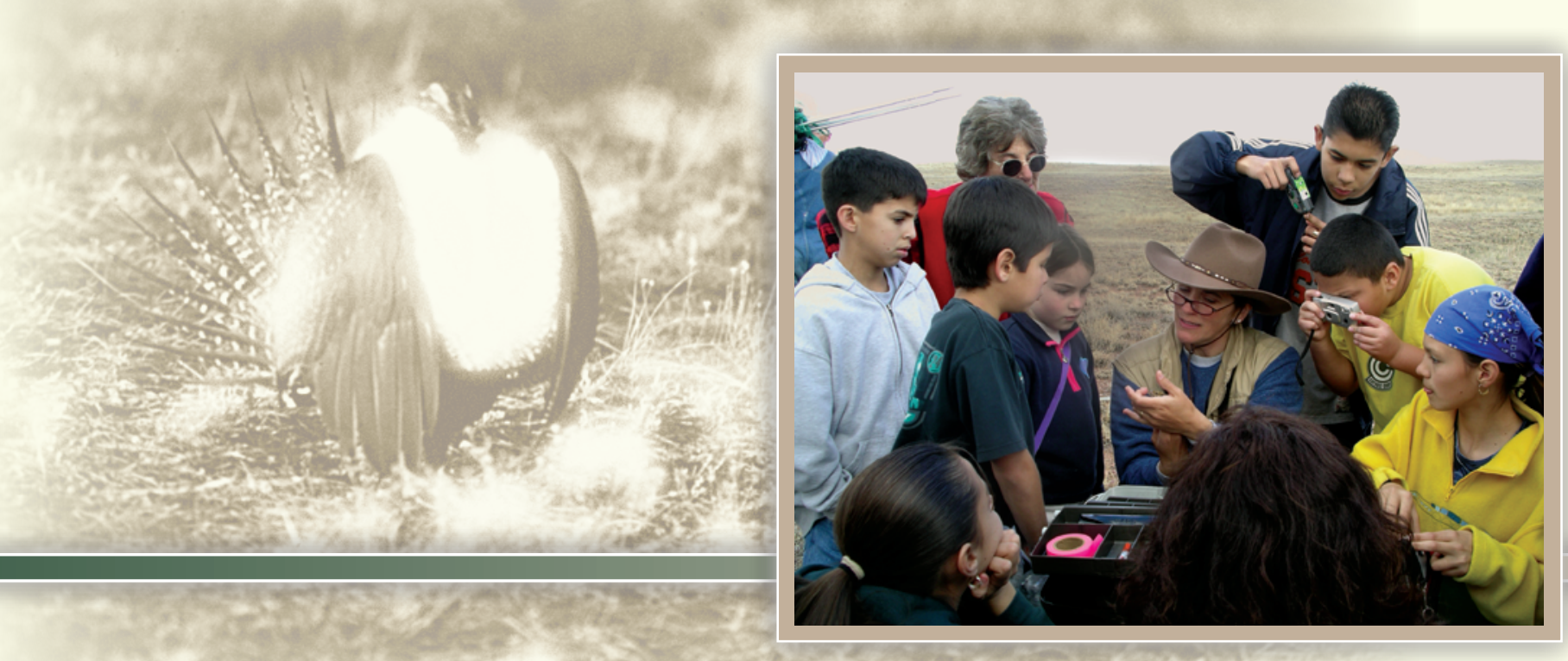

Trust Species and Habitats are the focus of FORT scientists who investigate why certain species are declining and what can be done to improve their status. This work directly supports development of species management and recovery plans. We conduct research and provide inventory and monitoring, population studies, genetic and stable isotope analyses, disease ecology investigations, and development of novel statistical and field methods.

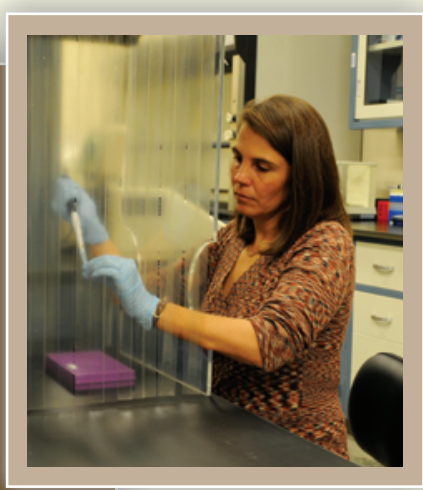

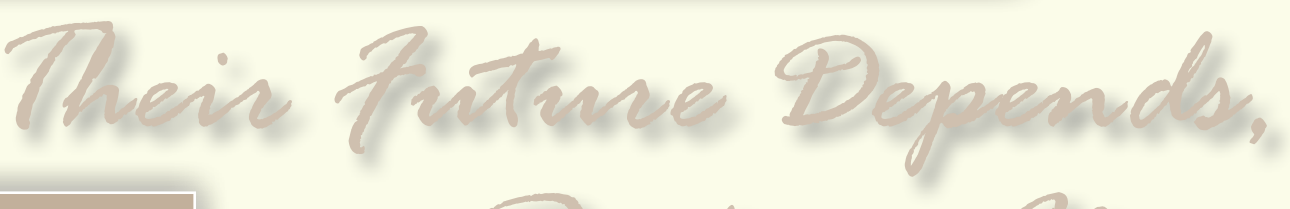

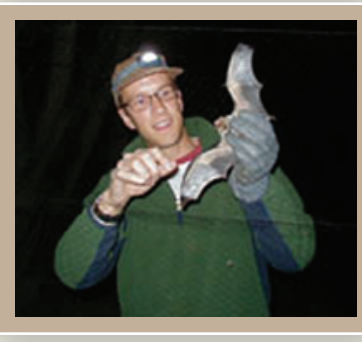

inn Pantion 20. 


\section{Engage with Us}

www.fort.usgs.gov

970.226.9100 
무

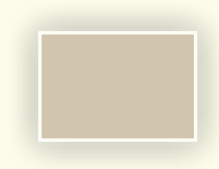
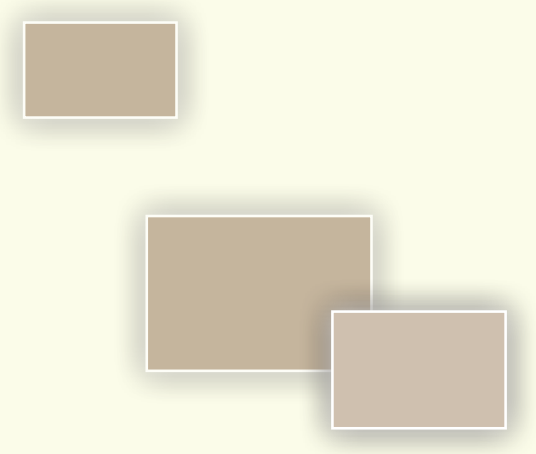